\title{
Expanding and Contracting Definitions of Syncopation: Commentary on Temperley 2019
}

\author{
NAT CONDIT-SCHULTZ[1] \\ Georgia Institute of Technology
}

\begin{abstract}
In the article Second-Position Syncopation in European and American Vocal Music, David Temperley presents an empirical, socio-cultural survey of syncopation in 19th-century Western music. He espouses the following novel ideas about operational definitions of syncopation: 1) that syncopations on the second position of a duple hierarchy are musically, and culturally, distinct from fourth-position syncopations; 2) that more detailed operational definitions of syncopation, what Temperley calls "acute" syncopations, are needed to properly understand syncopation. Following up on Temperley's work, I apply his definitions of syncopation to a corpus of more recent Anglo-American popular music (Gauvin, Condit-Schultz, \& Arthur 2017). I discuss how Temperley's definitions must be adapted and expanded to fit this different, more diverse, dataset, proposing several new syncopation definitions of my own. I also discuss some statistical assumptions that ought to be better addressed in future work, and speculate on how inconsistencies of music notation might hinder historical studies like Temperley's.
\end{abstract}

Submitted 2019 August 30; accepted 2019 August 30.

KEYWORDS: syncopation, corpus analysis, methodology, rhythm

IN Second-Position Syncopation in European and American Vocal Music, David Temperley presents several novel insights about the nature and history of syncopation in Western music. The paper argues that common operational definitions of syncopation, including Longuet-Higgins and Lee's (1984) influential definition, are overly simplistic in two regards: First, Temperley presents the idea that syncopation at different metric positions is musically, perceptually, and culturally distinct; Temperley focuses on what he calls second-position syncopation, and illustrates that whilst second-position syncopation is fairly common in early Anglo-American music, fourth-position syncopation is absent. Second, defining syncopation purely on the relative metric position of onsets, ignoring duration and other musical features, is inadequate in fully describing the phenomenon. Such positional definitions give many false positives - for instance, identifying unaccented, non-sustained notes as syncopations where, Temperley argues, they are not really perceived as such. Temperley observes that such "weak" syncopations do occur in continental European song but not stronger syncopations, and argues convincingly that strong syncopations in British music contributed to the highly-syncopated nature of American music in later eras.

This paper is an excellent example of the fruitful synthesis of humanistic and empirical approaches to music research, representing computational corpus work driven by specific musical observations and theories. The paper also calls attention to the dangers of conducting empirical or computational work without a thoughtful musical perspective; empiricism requires clear, precise operational definitions, but if these definitions are overly reductive or insufficiently nuanced, we may miss important musical distinctions. The paper also suggests a clear path forward for future empirical studies of syncopation.

Temperley's longstanding interest in modern Anglo-American popular music is evident throughout the paper, as he frequently refers to the relevance of his study of 19th-century song to later music. Nonetheless, his discussions and definitions are very precisely molded to his 19th-century samples, which are relatively less syncopated compared to later popular song. Attempting to apply his ideas to later music will require additional operational decisions and exploration. To initiate this line of research, I offer below a quick exploration of syncopation in mid-to-late 20th-century Anglo-American popular music. I apply Temperley's analyses to this music, revealing just how much more syncopation occurs in this later music. I then suggest a few ways that Temperley's methods can be better adapted to late 20th-century pop music. My main point is to illustrate some of the methodological, especially operational, questions to be considered when attempting to study syncopation, or rhythm more broadly. 


\section{SYNCOPATION ON THE BILLBOARD CHARTS}

\section{Corpus}

The data I will use is drawn from an unreleased corpus currently being constructed by myself and several colleagues (Gauvin, Condit-Schultz, \& Arthur 2017). This corpus is an expansion of McGill University's Billboard corpus of harmonic transcriptions (Burgoyne, Wild, \& Fujinaga 2011). The McGill Billboard corpus consists of harmonic transcriptions of 739 songs which appeared on the Billboard Hot 100 chart between 1958-1991. We are currently working to add detailed transcriptions of vocal melodies in these 739 songs, with approximately 133 transcriptions completed so far. When complete, our corpus will serve as an interesting complement to Temperley and de Clercq's Rolling Stone Corpus (2013); however, and crucial to the current discussion, our corpus includes duration information for all notes, not simply inter-onset-intervals as the Rolling Stone Corpus does. Taking the 133 transcriptions at my disposal, I exclude all pieces and passages which are not in 4/4 time, leaving 124 songs in my dataset.

Though Temperley argues convincingly that the relative accent of ostensibly syncopated notes must be considered, he ignores one of the most crucial phenomenological accents in vocal music: Syllable stress (no doubt, this was done for practical, not principled, reasons). The importance of incorporating syllable-stress information in rhythmic analysis has recently been discussed by Tan et al. (2019) and has been highlighted in my own work as well (Condit-Schultz, 2016). Unfortunately, my current dataset does not yet include any syllable stress information, so I cannot expand upon Temperley's analyses in this regard.

\section{Temperley's definitions}

Based on Temperley's precise definitions, Table 1 shows the frequency of onset and acute syncopations in the current Billboard dataset.

Table 1. The number of occurrences of Temperley's two syncopation definitions across second- and fourth-positions (at the eighth-note level) in the Billboard corpus. This table emulates Temperley's Table 3.

\begin{tabular}{lcccc} 
& \multicolumn{2}{l}{ Onset Syncopations } & \multicolumn{1}{l}{ Acute Syncopations } \\
\cline { 2 - 5 } Position & $\begin{array}{l}\text { Occurrences } \\
\text { (per measure[2]) }\end{array}$ & $\begin{array}{l}\text { Songs containing } \\
\text { (percent) }\end{array}$ & $\begin{array}{l}\text { Occurrences } \\
\text { (per measure) }\end{array}$ & $\begin{array}{l}\text { Songs containing } \\
\text { (percent) }\end{array}$ \\
\hline Second & $1,563(.175)$ & $112(90)$ & $134(.015)$ & $40(32)$ \\
\hline Fourth & $2,095(.235)$ & $109(88)$ & $330(.037)$ & $62(50)$ \\
\hline
\end{tabular}

As might be expected, second-position onset syncopations are more than twice as prevalent in the Billboard data compared to Temperley's most syncopated (African-American) corpus. Interestingly, acute syncopations are about equally common in the Billboard data compared to Temperley's American corpora, though they appear in a much higher proportion of songs. Not surprisingly, fourth-position syncopations are even more common in Billboard hits than second-position syncopations.

\section{Expanding Definitions}

Temperley's definitions are overly-specified to his data in two respects: 1) his requirement that a syncopation must be preceded by an on-beat note; 2 ) his prescription that the inter-onset-interval/duration of an 8th-level syncopation must be at least a quarter-note. Temperley specifically notes the arbitrariness of the first of these restrictions, but notes that "virtually" no examples which violated this restriction appeared in his corpora. Temperley does not mention or justify his second restriction, but it is presumed to simply reflect again that few or no rhythms in his corpora suggested a problem with his rule. These two requirements may be reasonable in 19th and early 20th-century song books, but they are hard to ignore in Billboard pop music. 


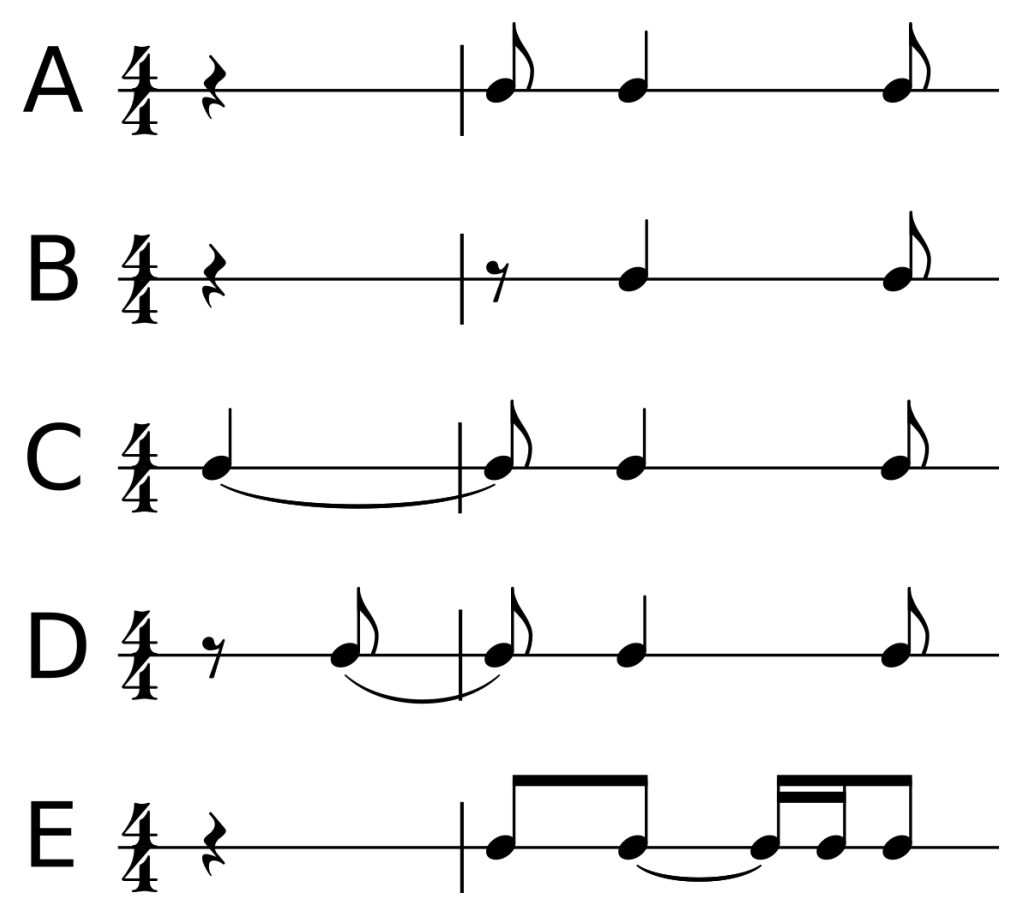

Figure 1. Example A fits Temperley's syncopation definitions while B-E do not. Examples A-D show "unanchored" syncopations.

Line A in Figure 1 is a rhythm which matches Temperley's definition of onset-syncopation at the eighthnote level. Lines B-D illustrate similar rhythms which do not satisfy Temperley's criteria for syncopation because they are not proceeded by an attack on the strong beat before them; presently, these are labeled "unanchored" syncopations. Lines C-D illustrate that unanchored syncopations are almost necessarily proceeded by another syncopation; we might think of these as "doubly syncopated". Finally, line E illustrates a potential problem with the second restriction mentioned above: A rhythm which does not meet Temperley's criteria because the syncopated note is less than a quarter-note in length.

If I allow any of the examples in Figure 1 to be considered onset syncopations, and adapt the acute-syncopation definition accordingly, I produce Table 2. As we would expect, removing Temperley's restrictions reveals far more syncopations in the music than previously seen. The results now reinforce that syncopations are indeed much more common in late 20th-century songs than in 19th-century songbooks.

Table 2. The number of occurrences of syncopation given my broadened definitions, which includes anchored or anchored syncopations and syncopations of any duration/inter-onset-interval. Eighth-note level only.

\begin{tabular}{lcccc} 
& \multicolumn{2}{l}{ Onset Syncopations } & \multicolumn{2}{c}{ Acute Syncopations } \\
\cline { 2 - 5 } Position & $\begin{array}{l}\text { Occurrences } \\
\text { (per measure) }\end{array}$ & $\begin{array}{l}\text { Songs containing } \\
\text { (percent) }\end{array}$ & $\begin{array}{l}\text { Occurrences } \\
\text { (per measure) }\end{array}$ & $\begin{array}{l}\text { Songs containing } \\
\text { (percent) }\end{array}$ \\
\hline Second & $3,099(.348)$ & $119(96)$ & $210(.024)$ & $51(41)$ \\
\hline Fourth & $4,055(.456)$ & $121(976)$ & $528(.059)$ & $80(65)$ \\
\hline
\end{tabular}

\section{Narrowing Comparisons}

As Temperley admits, his definition of acute syncopations adds three unrelated additional features to the "normal" onset-based syncopation definition: That they be syllabic, continued, and approached by ascending leap. Adding these features together obscures which of the three features is most influential. My immediate intuition was that the relative rarity of Temperley's acute syncopations is due to the ascending leap criterion; indeed, ascending melodic leaps represent only $12.2 \%$ of the intervals in the Billboard corpus, so this criterion is guaranteed to result in fewer examples. I decided to focus my next analysis on one dimension: The onset vs continued dichotomy. Accordingly, I compare two new definitions of syncopation: 1) curtailed syncopation: Syllabic onset syncopations which do not sustain (i.e. are followed by a rest on the next strong beat); 2) agogic syncopations: Syllabic onset syncopations 
which "continue" (sustain) over the next strong beat. In either case, I count only syllabic onsets but include any melodic interval.

Table 3. The number of occurrences of two new syncopation definitions, curtailed and agogic, which differ only in the duration of their notes. Eighth-note level only.

\begin{tabular}{lcccc} 
& \multicolumn{2}{l}{ Curtailed Syncopations } & \multicolumn{2}{l}{ Agogic Syncopations } \\
\cline { 2 - 5 } Position & $\begin{array}{l}\text { Occurrences } \\
\text { (per measure) }\end{array}$ & $\begin{array}{l}\text { Songs containing } \\
\text { (percent) }\end{array}$ & $\begin{array}{l}\text { Occurrences } \\
\text { (per measure) }\end{array}$ & $\begin{array}{l}\text { Songs containing } \\
\text { (percent) }\end{array}$ \\
\hline Second & $497(.056)$ & $79(64)$ & $2,123(.239)$ & $113(91)$ \\
\hline Fourth & $389(.044)$ & $71(976)$ & $3,381(.380)$ & $117(94)$ \\
\hline
\end{tabular}

Exactly as anticipated, Temperley's "ascending-leap" criterion was the major filter accounting for the small number of acute syncopations; my more general "agogic syncopation" is extremely common. In contrast, "cut syncopations", which do not sustain onto the next beat, are relatively rare, with secondposition cut syncopations being more common than fourth-position ones (reversing the pattern seen elsewhere). I interpret these observations as fitting Temperley's general idea that "cut off" syncopations (which do not sustain across the strong beat) are not "really" syncopations (in some sense).

I do not really want to suggest that any of these analyses illustrate problems with Temperley's definitions, so much as additional complexities to consider. Do these additional definitions (e.g., anchored vs unanchored, doubly vs singly syncopated, ascending vs descending, leap vs step) add to our understanding of the phenomenon? Do we perceive them as distinct? These questions cannot be answered here, but I am grateful that Temperley has started the dialogue around thinking of syncopation as being a non-dichotomous, subjective phenomenon. Perhaps, syncopation is neither "all-or-nothing" (dichotomous) or "more-or-less" (one dimensional), but in fact a nuanced multidimensional feature of rhythm in music.

\section{Other Levels}

I will not take much time here, but I can note that 16th-note syncopations are also common in the Billboard data, with some 32nd-note syncopation present as well. One important question is whether there might be syncopations at higher levels as well; for instance, quarter-note syncopations, which seem quite plausible at fast tempos, and half-note syncopations, which seem less plausible but cannot be impossible. Another question is whether treating syncopations at different levels differently is warranted; perhaps, instead, we ought to bring all levels together.

\section{STATISTICAL CONCERNS}

\section{Normalization}

Aside from the issue of defining syncopation, there are several statistical issues to consider. Firstly, Temperley normalizes his data by counting the proportion of syncopations per measure. However, note frequency, syncopated or otherwise, is variable across metric positions, so it might be more realistic to count the number of syncopations as a proportion of notes on each metric position. Overall, my dataset includes 6,765 syllables sung on second-eighth-note positions and 8,535 syllables sung on fourth-eighthpositions. Thus, second-position eighths are simply rarer than fourth-position in general, which may affect the balance between the two positions when tabulating syncopations. Table 4 shows the per-note proportion of various syncopation definitions for second- and fourth-position eighth-notes in the Billboard data. 
Table 4. The number of occurrences of eighth-level syncopations, and the proportion they make up of total notes in their eighth-note metric position, in the Billboard dataset. The "broadened" definitions are my expansions of Temperley's definitions to include unanchored syncopations and syncopations of any length.

\begin{tabular}{lrrrr} 
& \multicolumn{3}{c}{ Second Position } & \multicolumn{2}{c}{ Fourth Position } \\
\cline { 2 - 6 } Definition & Occurrences & Proportion & Occurrences & \multicolumn{1}{c}{ Proportion } \\
\hline Onset (broadened) & 3,099 & .458 & 4,055 & .475 \\
\hline Acute (broadened) & 210 & .031 & 528 & .062 \\
\hline Curtailed & 497 & .073 & 389 & .046 \\
\hline Agogic & 2,123 & .314 & 3,381 & .396 \\
\hline
\end{tabular}

The results are not dramatically different than the per-measure results. However, the fact that secondposition notes are slightly less common overall is reflected in a narrowing of the gap between secondposition and fourth-position proportions when a per-note normalization is used.

To generalize somewhat, one final question can be asked: What proportion of notes on any position, at any metric level, are syncopated in the Billboard data (the dataset includes 37,386 notes)? There are a total of 10,540 onset syncopations, making up $28.1 \%$ percent of notes; in contrast, 923 examples of Temperley's acute syncopations appear, making up only $2.4 \%$ of the corpus. Finally, my agogic syncopation definition matches 7,413 notes in the dataset, making up $19.7 \%$ of the notes. This final approach is worthwhile in part because it is comparable to the definition I have used in my study of rap (Condit-Schultz, 2016); these numbers (ranging from $20 \%-28 \%$ or so) are broadly consistent with my (stressed-syllable, onset-based) analyses of syncopation in rap music.

\section{Data Dependence}

These analyses treat individual notes as independent statistical samples. However, two occurrences of syncopation within the same song likely reflect a repeating motive, section, or general rhythmic style of the song. Thus, treating them as unrelated events appears problematic, especially given highly heterogeneous sets like the Billboard chart. Some songs may have few or no syncopations, while others have many; this stylistic variability is ignored by generalizations across the whole set.

Though $31 \%$ and $40 \%$ of second- and fourth-position notes in the dataset overall are agogic syncopations, these numbers range from $0 \%$ to $100 \%$ in either position across the 124 pieces in the dataset. In other words, there are songs in the corpus where every second-position note forms an agogic syncopation and others where none do - the same can be said for fourth-position notes (though they are not necessarily the same songs[3]). If even a handful of these extreme songs were missing from the dataset, the overall averages might shift significantly.

\section{HOW RELIABLE IS NOTATION?}

I would like to take one more section to speculate about a possible problem with Temperley's approach. Unlike the Billboard data I am using, Temperley's study, necessarily, relies on music notation. One important question is how reliable music notation is at indicating syncopation in 19th-20th century songbooks. It is easily observed that notation of 20th-century songs often does not match the rhythms of their performers; whether these mismatches reflect performers adding syncopation to a simpler, underlying cognitive representation (represented in the notation), or that the notation omits details that are difficult to read or notate, is not clear. It seems possible at least, that syncopations might have been performed that are not notated. This conjecture would only prove problematic to Temperley's argument if different musical cultures are more likely to add syncopation. Since we know that later American musical traditions frequently elide syncopations in notation, it does not seem implausible that this practice may have existed in Slave Songs of the United States or even A Treasury of American Song. That the practice might have occurred in European song traditions seems less likely, though it cannot be discounted. In any case, unless French, German, and Italian performers were systematically eliding syncopations in notated music at a much higher rate than British or American performers, Temperley's conclusions about the contrast between continental and British/American syncopation usage are likely solid.

Another interesting possibility — which is not germane to Temperley's main arguments — is that second- and fourth-position syncopations are more likely or less likely to be elided. Perhaps the relative infrequency of fourth-position of syncopation in 19th century song books might reflect a reluctance to 
notate them, rather than their actual absence. Since audio recordings of authentic performances from the music and era Temperley is studying are not available, we may never resolve these questions definitively.

\section{ACKNOWLEDGEMENTS}

This article was copyedited by Scott Bannister and layout edited by Diana Kayser.

\section{NOTES}

[1] Correspondence can be addressed to: Nathaniel Condit-Schultz. E-mail: natcs@gatech.edu. http://fathermckenzie.net

[2] Since my transcriptions include measures where the vocalists are tacit (i.e., instrumental passages) I divide by the total number of measures which contain at least one vocal note.

[3] Though the proportion of second- and fourth-position syncopations across the 124 pieces are quite correlated $(r=.61)$.

\section{REFERENCES}

Burgoyne, J. A., Wild, J., and Fujinaga, I. (2011). An Expert Ground Truth Set for Audio Chord Recognition and Music Analysis. In A. Klapuri and C. Leider (Eds.), Proceedings of the 12th International Society for Music Information Retrieval (ISMIR) Conference (pp. 633-38). Miami, FL.

Condit-Schultz, N. (2016). The Musical Corpus of Flow: A digital corpus of rap transcriptions. Empirical Musicology Review, 11(2), 124-47. https://doi.org/10.18061/emr.v11i2.4961

Gauvin, H. L., Condit-Schultz, N., and Arthur, C. (2017). Supplementing Melody, Lyrics, and Acoustic Information to the McGill Billboard Database. Presented at DH2017: Annual Conference of the International Alliance of Digital Humanities Organizations. Montréal, QC.

Longuet-Higgins, H. C., and Lee, C. S. (1984). The Rhythmic Interpretation of Monophonic Music. Music Perception, 1(4), 424-41. https://doi.org/10.2307/40285271

Tan. I., Lustig. E., and Temperley, D. (2019). Anticipatory Syncopation in Rock: A Corpus Study. Music Perception: An Interdisciplinary Journal, 36(4), 353-70. https://doi.org/10.1525/mp.2019.36.4.353

Temperley, D., and de Clercq, T. (2013). Statistical Analysis of Harmony and Melody in Rock Music. Journal of New Music Research, 42(3), 187-204. https://doi.org/10.1080/09298215.2013.788039 